\title{
La piedra con figuras rupestres de don Federico Marés
}

\author{
Eduardo Ripoll Perello
}

El título de la presente nota hace referencia a una pieza que fue del insigne escultor y académico don Federico Marés y Deulovol (Port Bou, Alt Empordà, 1893 - Barcelona, 1991) ', y de la cual nos hizo donación personal en 1981. Se trata de un fragmento de roca con pinturas rupestres que llegó a las manos del señor Marés al adquirir, hace muchos años, a un anticuario andaluz (¿Córdoba?) un lote de piedras esculpidas destinadas a su conocido museo de la ciudad de Barcelona. En el verano de 1986, en una visita a su taller, el señor Marés dio su conformidad para que el que esto escribe, a la sazón director del Museo Arqueológico Nacional, hiciera donación de la roca a dicho museo madrileño. El acta de entrega y donación se verificó en 17 de octubre de $1986^{2}$.

La Piedra Marés es un fragmento de caliza granulosa que sirve de soporte a unas pinturas rupestres esquemáticas y que es evidente que fue arrancado de su contexto. Las dimensiones de la roca son: $43,5 \mathrm{~cm}$

Artista escultor, profesor, coleccionista, erudito y fundador de museos (el más importante es el que lleva su nombre, creado en 1946 por consejo de su amigo Eugenio D'Ors y que puso bajo los auspicios del Ayuntamiento de Barcelona quedando instalado en parte del que fue palacio de los condes de Barcelona y reyes de Aragón). Su obra escultórica está muy dispersa (en Barcelona: estatuas de la plaza de Cataluña, 1929; monumentos a Francesc Layret, 1933; estatua de la Victoria, 1939). Restauró en 1946 las tumbas reales del monasterio de Poblet, con criterios que seguramente no serian los actuales. Profesor (desde 1914), catedrático (desde 1943) y director (1946-1964) de la Escola de Belles Arts de Llotja -antecedente de la Facultad de Bellas Artes-, académico de número de la Real Academia de Bellas Artes de San Fernando, de la Real Acadèmia de Belles Arts de Sant Jordi (presidente, 1960-1990), etc. Escribió una monografia sobre las tumbas reales de Poblet (1952), la recopilación Dos siglos de enseñanza artistica en el Principado (1964) y los recuerdos de su vida en El mundo fascinante del coleccionismo y de las antigüedades, memorias de la vida de un coleccionista (1977), amén de muchas obras y trabajos menores.

2 Archivo del Museo Arqueológico Nacional, Madrid (con las firmas de la doctora doña Carmen Cacho Quesada, conservadora jefe de la Sección de Prehistoria; don Antonio Montero Torres, secretario del Museo, y del donante, autor del presente texto). 
de longitud, $37,5 \mathrm{~cm}$ de anchura y $16 \mathrm{~cm}$ de espesor. Sobre la superficie patinada del fragmento, que presenta algunas huellas del brutal arranque, hay tres representaciones antropomorfas completas y dos incompletas (de la forma llamada "lagarto", "salamandra», o más apropiadamente "de brazos y piernas en arco», como se dirá más adelante). Las figuras que están enteras miden $20 \mathrm{~cm}$ de altura. La cabeza está reducida a un pequeño muñón. Tanto los brazos como las piernas están formados por un arco, muy largo en aquéllos y muy corto en éstas. Entre las extremidades inferiores, continuando la linea recta del tronco, se representó un exagerado falo. Esta descripción vale para las cinco figuras. Su color es rojo vinoso muy oscuro, bien impregnado en la roca (figs. 1 y 2).

Lamentablemente, el caso de esta roca arrancada no es el primero en el arte prehistórico español. Ya en los mismos comienzos de la investigación de la facies levantina del arte postpaleolítico, el descubridor de la misma, Juan Cabré Aguiló (1882-1947), arrancó varias figuras de la Roca dels Moros y del Barranc dels Gascons en el paraje de Calapatá (Cretas, Teruel), precisamente el de dicho descubrimiento. En la operación se perdieron varias figuras. Al parecer fue realizada después de 1903 y antes de 1908. Para ello se puede aducir un fragmento de una carta de Hermilio Alcalde del Rio al abate Henri Breuil (1877-1961) fechada el 8 de febrero de 1908 y que dice: “Por fin me han escrito, después de varias cartas, del Bajo Aragón; le adjunto la carta que me remite la persona a quien escribi últimamente [Santiago Vidiella]; por cierto que lo hice dos veces, la última certificada y con acuse de recibo. Como usted observará por dicha carta, las pinturas fueron arrancadas de cuajo de los muros que las contenian y transportadas a un museo particular; esto corrobora lo que dice la nota que reproduce el articulo que sobre dichas pinturas apareció en el Boletín de Geografia e Historia del Bajo Aragón, cuyo número se lo mandé a usted con los planos. Las principales pinturas, por tanto, creo que habria que buscarlas en Calaceite, en la colección del que se las llevó, y las restantes, de menos importancia, supongo permanecerán en el sitio de su hallazgo, que supongo habrá quedado destrozado al arrancar aquéllas. Usted ordenará, informado ya sobre el particular» ${ }^{3}$. En una carta del 17 de noviembre del mismo año 1908, es el propio Cabré el que le dice al abate Breuil: "Los ciervos últimos los arranqué y están en mi poder» ". Unos años después, en 1915, Cabré habló de la voladura llevada a cabo

Archivo E. R. Es la misma carta en la que le informa del descubrimiento de la cueva de El Pendo (Cantabria). El trabajo mencionado del Boletin de Geografia e Historia del Bajo Aragón es el de Santiago VIOIELLA, "Las pinturas rupestres del término de Cretas" (t. 1, 1907, pág. 68), que en esta ocasión no hemos podido cotejar

${ }^{4}$ Archivo E. R. 


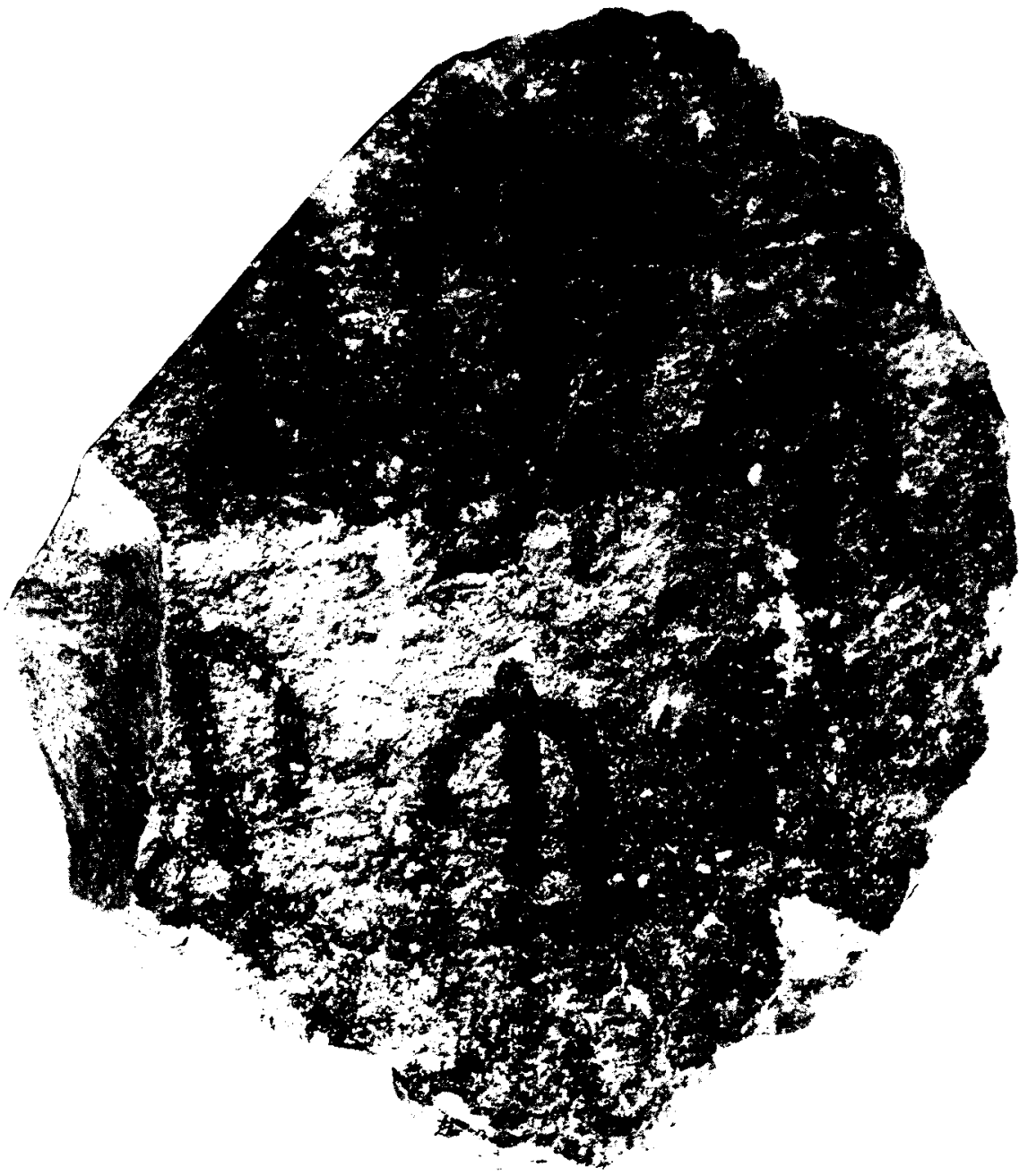

Fig. 1. La piedra Marés (Museo Arqueológico Nacional, Madrid). 
por un alfarero supersticioso, pero, al propio tiempo, escribió: "Gracias que con anterioridad habia tenido el autor la previsión de arrancar las tres mejores figuras de ciervos, que conserva en su colección particular, viendo que no habia un medio seguro de conservarlas. Intactas habian estado hasta 1903 que las descubrió; a los pocos dias de haberlas copiado ya las habian mutilado; los pastores las escogieron como blanco para sus pedreas, con las que iban destrozándolas poco a poco" ${ }^{5}$. Los tres magníficos ciervos de referencia fueron adquiridos años más tarde por el Museo Arqueológico de Barcelona, donde se conservan ${ }^{6}$. Parece ser que hay otra figura en una colección particular de Calaceite, lo que no hemos podido confirmar.

Juan Cabré llevó a cabo asimismo una operación análoga con una curiosa representación (¿idolo?) del conjunto esquemático de El Poyo de Enmedio (Aldeaquemada, Jaén). El propio Cabré explicó: «... fue arrancada de su sitio para el Museo Nacional de Ciencias Naturales, ante el temor de que se perdiera, pues amenazaba desprenderse gran parte de la roca con la figura pintada en la peña..." ${ }^{7}$. El abate Breuil, en su gran obra de conjunto sobre el arte esquemático, describe la enigmática figura e indica: «... elle a été detruite entre ma visite et celle de $M$. Cabré. Le dessin que ce dernier a publié n'est que la copie de celui que je lui avais communiqué»" ${ }^{8}$. La fecha del arranque hay que situarla entre 1913 y 1917. Los restos conservados in situ han sido descritos por López Payer y Soria Lerma ${ }^{9}$. Es posible que el fragmento rocoso se conserve en alguna de las reservas o almacenes del indicado museo.

Merecen ser citados, asimismo, los importantes destrozos que sufrieron los abrigos pintados del gran conjunto de La Valltorta (Castellón) des-

${ }^{3} \mathrm{H}$. Breuil y J. Cabre, "Les peintures rupestres du bassin inférieur de l'Ebre. I. Les rochers peints de Calapatá à Cretas (Bas Aragon)", L'Anthropologie, XX, 1909, págs. 1-21. Juan CABRE AGuILO, El arte rupestre en España (regiones septentrional y oriental), CIPP núm. 1. Madrid, 1915, págs. 129-144, figs. 70-73, láms. V-IX (el texto sobre el arranque, en las págs. 135-136). Descubrimientos y ambiente de esta época: E. Ripoll Perello, "Vida y obra del abate Henri Breuil, padre de la Prehistoria", Miscelánea en homenaje al abate Henri Breuil (1877-1961), Barcelona, IPA, 1964, t. I. págs. 1-70, 8 figs. y XXV láminas.

"Martín Almagro, "Las pinturas rupestres del Bajo Aragón", cap. IV (págs. 40-50) de Martín Almagro, Antonio Beltran y Eduardo Ripoll, Prehistoria del Bajo Aragón, Zaragoza, 1956 (donde se reproducen los calcos de Luisa y Eduardo Ripoll, conservados en el Museo Arqueológico de Barcelona, en los que quedan indicadas las huellas del arranque que presentan los abrigos).

J. Cabre Aguilo, Las pinturas rupestres de Aldeaquemada, CIPP núm. 14, Madrid, 1917 pág. 23.

${ }^{8}$ Henri Breull, Les peintures rupestres schématiques de la Péninsule lbérique, Lagny. 1933, t. III, pág. 16, lám. IX. 2.

${ }^{9}$ Manuel Gabriel Lopez Payer y Miguel Soria Lerma, El arte rupestre en Sierra Morena oriental, La Carolina (Jaén), 1968, págs. 49-50, lám. 9 


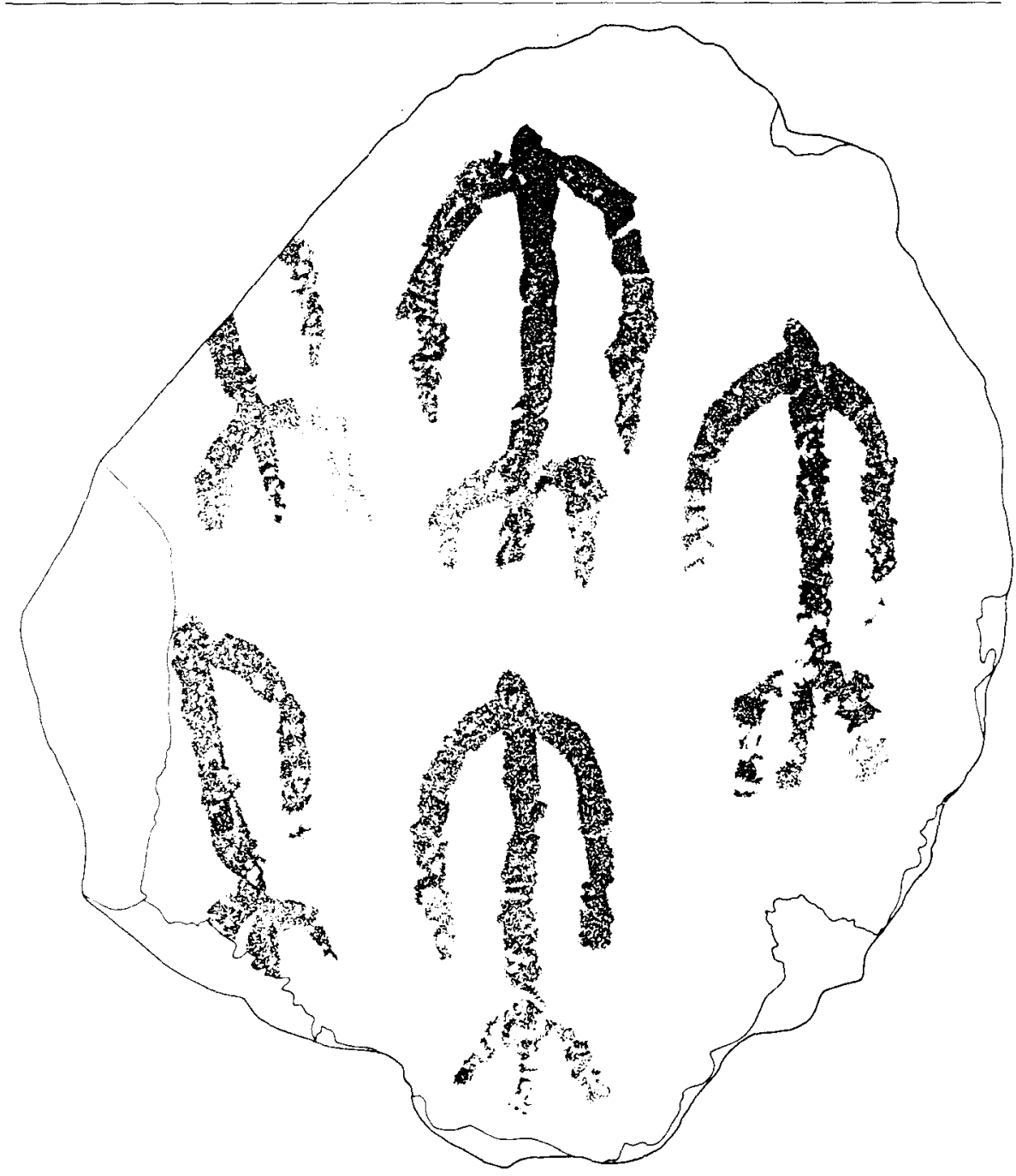

Fig. 2. Calco de los antropomorfos de la piedra Marés.

de la época misma de su descubrimiento y primeros estudios ". Asi, de la Cova del Civil se arrancaron por entonces varias figuras, hecho que fue denunciado por Juan Cabré en $1923^{11}$. En la monografia de La Valltorta, que en 1982 dirigió Ramón Viñas, hay varias referencias a las destrucciones y en la parte por él escrita hace el siguiente balance: "Esta

"Hugo Obermaier y Paul Wernert, Las pinturas rupestres del Barranco de Valltorta (Cas- 
adversa acción antrópica comprende una lista interminable de destrucciones, siendo los abrigos más afectados el del Rull, con diversos personajes mutilados; la Cova dels Tolls Alts, donde fue arrancada una cierva (fig. 170), y la Cova dels Cavalls, arrasada por los asiduos visitantes que llegaron incluso a sustraer las figuras números 43 a la 48,57 y 58 (fig. 185) y destruir gran parte de las números 13 a 18 y las 37 (fig. 264), según la numeración de $H$. Obermaier. Cabe indicar que una de estas figuras, concretamente la número 57 , se encuentra en el Museo de Cervera, en Lérida (fig. 251, núm. 1). En los paneles de La Saltadora se extrajeron numerosas figuras y curiosamente algunos detalles que habian sido destacados en el estudio de $H$. Obermaier y $P$. Wernert, lo cual no podía haber sido obra de un labriego sino de alguien que conocía perfectamente el tema, pues sería ilógico pensar que sólo destruyera un pequeño detalle y dejara intacto el resto de la figura. Algunos de estos fragmentos arrancados corresponden a la figura número 50 del citado estudio, de la que se comentaba: "... cuyo rasgo no puede considerarse como modelo de retrato, a pesar de la buena ejecución de los detalles...". La mencionada cara fue destruida, junto con otro detalle del que se decia: "... las últimas dudas quedarian disipadas por la adjunta figura número $60 .$. Este tirador tiene fijado el dardo del tal modo a la cuerda, que la emplumadura viene a estar situada junto a su mano...". Esta emplumadura fue el único fragmento arrancado de la figura (fig. 244)»" ${ }^{12}$.

En relación con el texto transcrito debemos indicar que, efectivamente, la representación de un arquero vistiendo zaragüelles $\left(n .^{\circ} 57\right.$ ) que $R$. Viñas cita, fue comprada por el Museo Durán y Sanpere, de Cervera (Lérida), donde se exhibe. Para su conservación, el fragmento está engastado

tellón), CIPP núm. 23, Madrid, 1919; A. Durán i Sanpere y M. Pallarés, "Exploració arqueològica del Barranc de la Valltorta", Anuari de l'Institut d'Estudis Catalans, Vl, 1915-1920. págs. 444-454, figs. 47-62, y 3 láms. s/n. (que se complementa con M. PaLlarés, “Exploració des jaciments prehistòrics de la Valltorta", en el mismo vol., págs. 454-457, figs. 63-70); $E$. RIPOLL Perello, "Noticia sobre l'estudi de les pintures de "La Saltadora" (Barranc de La Valltorta, Castellón)", Cuadernos de Arqueologia e Historia de la Ciudad, XV, 1970 (Estudios dedicados a Durán y Sanpere en su $L X X X$ aniversario, III), págs. 9-24, 6 figs. y III láminas.

' J. Cabré y Aguilo, "Las pinturas rupestres de la Valltorta. I, Desaparición de una de las estaciones prehistóricas de este valle". Actas y Memorias de la Sociedad Española de Antropología, Etnografia y Prehistoria, II, 1923, págs. 107-118. El texto incluye una acusación a los "otros", que no sabemos si alude a los demás investigadores o a la "politica", puesto que Cabré estaba entonces bajo la jefatura del marqués de Cerralbo, importante figura del tradicionalismo carlista, ideología que gozaba de gran predicamento en el Maestrazgo y otras comarcas castellonenses y turolenses.

12 Ramón Viñas (dir.), La Valltorta, Barcelona, Castell, 1982, págs. 182-185 (las figuras que se indican son las de este libro). 
en una base de yeso. Su fotografía fue dada a conocer por Antonio Beltràn ${ }^{13}$.

También es obligado hacer referencia a las pinturas de facies levantina de la Cañada de Marco, en Alcaine (Teruel), descubiertas en 1964 o 1965 y publicadas por Teógenes Ortego y Frias que únicamente señaló: «... el desprendimiento de numerosos bloques de lo que fue la primitiva visera del abrigo...» ${ }^{14}$. Pero ya Beltrán, en 1968, o sea en fechas inmediatas a las del hallazgo, indicó que las pinturas habian sufrido «... numerosos atentados por turistas desaprensivos" ${ }^{15}$.

Después de esta lamentable historia, volvamos a la Piedra Marés. Nuestra impresión es que esta pequeña y bella muestra, típica y característica de la facies esquemática del arte rupestre postpaleolitico, debe proceder de algún lugar de Sierra Morena, al norte o al sur de la misma. Sería interesante - y esto es un llamamiento a cuantos trabajan en el arte de dicha región- averiguar la procedencia exacta, pues la operación de arranque debió dejar muy evidentes señales. Con ello, acaso se podrian descubrir otras figuras pintadas que, con las que nos ocupan, formarian un friso más extenso, como es habitual en esta etapa artistica. En todo caso permitirian su ubicación geográfica, aumentando de este modo la correspondiente cartografia de distribución (cf. más adelante).

Seria muy interesante averiguar en qué fase del proceso de esquematización se encuentran nuestras figuras, sus antecedentes y sus consecuentes. Desde el punto de vista morfológico, la seriación de las figuras antropomorfas del arte rupestre postpaleolítico es relativamente fácil. Pero, ¿podemos estar seguros de que los tipos se producen en una estricta evolución de la forma y a qué ritmos, o con que retrasos, se habrá producido en las diferentes regiones?

A nuestro parecer el tipo de antropomorfo que nos ocupa deriva directamente de las figuras "filiformes" propias de la facies levantina terminal. Podemos aducir algunos ejemplos, que sería posible multiplicar. Asi, los personajes de la Cova del Civil de La Valltorta (del tipo «nematomorfo" que deriva del "cestosomático" - que a su vez está precedido

\footnotetext{
13 Antonio Beltran Martinez, Arte rupestre levantino, Monografias arqueológicas, IV, Zaragoza, 1968. pág. 17, fig. 4.

${ }_{14}$ Teogenes Ortego y Frias, "Una nueva estación de arte rupestre en el término de Alcaine (Teruel)", (E. Ripoll. Perelló, ed.). Simposio Internacional de Arte Rupestre. Barcelona. 1966, Barcelona, IPA, 1968, págs. 149-163, 18 figuras.

B Beltran, Arte rupestre levantino, cit., pág. 134, fig. 88.
} 
por el «paquipodo»- en la nomenclatura de Obermaier y Wernert) ${ }^{16}$; los de la Coveta de Montegordo, que Viñas califica de tipo «estilizado y lineal»; el probable recolector del Cingle del Mas d'en Salvador, o los que componen una posible danza ritual del Cingle de l'Ermita ${ }^{17}$. También se pueden citar al respecto los arqueros de la danza bélica del abrigo del Roure, en Morella la Vella (Castellón), o los de El Polvorín (Pobla de Benifasà, Castellón) (fig. 3). El proceso de esquematización de la facies levantina final está muy bien individualizado en la parte central del abrigo de Los Grajos I (Cieza, Murcia) ${ }^{18}$. Además, la transición del tipo filiforme hacia lo que serán las formas esquemáticas, como las de la Piedra Ma-



Fig. 3. Guerrero filiforme de la Cueva del Polvorin (Castellón).

16 Obermaier y WeRnert, Las pinturas rupestres del barranco de Valltorta..., cit., pág. 27, fig. 10. Además de los «filiformes», en la Cova del Civil están presentes los inmediatos antecedentes de la forma; VIÑAS, La Valltorta, cit., págs. 118-123, figs. 161, 162 y 247. Los tres tipos de figuras humanas de Obermaier y Wernert, en la misma obra de Viñas, fig. 251, que hay que confrontar con su cuadro muy completo de la fig. 252.

17 VIÑAS, La Valltorta, cit., págs. 110-111, fig. 147; pág. 112, fig. 150, y pág. 116, fig. 157

18 A. Beltran Martinez, "Aportaciones de la Cueva de Los Grajos (Cieza, Murcia) al conocimiento del arte rupestre levantino español". (E. ANATI, ed.), Valcamonica Symposium, Capo di Ponte, 1968, págs. 79-85, 2 figs.; ID., Arte rupestre levantino, cit., págs. 224-226, fig. $143 \mathrm{a}$. 
rés, puede estudiarse en la Cueva de la Vieja, de Alpera, o en Minateda (ambos lugares en la provincia de Albacete) ${ }^{19}$.

Otra cuestión que habria que abordar es la de la "lateralidad" de las figuras humanas levantinas y la "frontalidad" de las esquemáticas. Acaso este podría ser uno de los criterios para establecer la frontera entre unas $y$ otras, y la separación entre ambas facies que tanta tinta ha hecho correr.

Por ser la única obra de conjunto sobre el arte esquemático con que contamos después de la del abate Breuil, y aunque casi ha transcurrido un cuarto de siglo desde su publicación, debemos citar y tener en cuenta aqui el libro del Pilar Acosta ${ }^{20}$. Acerca de los antropomorfos, esta autora escribe lo siguiente: "Respecto a la figura humana absolutamente esquemática y en si misma considerada, no habria que dudar, dado el antecedente de la pintura levantina, en hacerla derivar de ella, según pondrian de manifiesto las figuras de transición que en varios abrigos del Levante y del Sudeste aparecen superpuestas a las más naturalistas, típicas de esta zona. En este aspecto la figura humana esquemática sería una simple degeneración estilistica de los hombres y mujeres representados en las estaciones rupestres de estas zonas". Plantea Acosta, a continuación, la dificultad de establecer las tipologías - tan propia de todo el arte rupestre - y en particular el problema del "por qué de la variedad de formas representativas "tipo" que se repiten constantemente y con no demasiadas variantes por toda España; ¿a qué obedecen? En este sentido, seria necesario admitir un cambio de mentalidad impuesto por una nueva corriente cultural». Con ello admite que esa corriente «influyó acusadamente, y aunque sólo fuese en lineas generales, en la formación de los motivos humanos que se repiten en el fenómeno esquemático" ${ }^{21}$. Estima, por tanto, que a la suma de los dos factores se debería la variedad de las formas de las figuras humanas y animales de la facies esquemática. Por este motivo, en un intento reductor necesario en una obra de conjunto, establece una tipología básica de ocho modelos. De ellos, el que a

${ }^{19}$ H. Breull, P. Serrano Gomez y J. Cabre Agullo, "Les peintures rupestres d'Espagne. IV, Les abris del Bosque à Alpera (Albacete)», L'Anthropologie, XXIII, 1912, págs. 529-562, 14 figs. y IV láminas: $H$. Breull, "Les peintures rupestres de la Pénisule lbèrique. $X I$, Les roches peintes de Minateda (Albacete)", L'Anthropologie, XXX, 1920, págs. 1-50, 46 figs. y IV láminas; E. HeRnandez-PACHeCo, Las pinturas prehistóricas de las Cuevas de la Araña (Valencia). Evolución del arte rupestre en España, CIPP núm. 34, Madrid, 1924; E. RipoLL Perello, “Cuestiones en torno a la cronología del arte rupestre postpaleolítico en la Península Ibérican, Simposio Internacional de Arte Rupestre, Barcelona, 1966, cit. págs. 165-192.

? Pilar Acosta, La pintura rupestre esquemática en España, Salamanca, Universidad, 1968.

2 Acosta, La pintura rupestre esquemática..., cit., págs. 25-26 
nosotros nos interesa es el que denomina "figura humana de brazos en asa". Por nuestra parte pensamos que la calificación de "tipo" o "subtipo" dependerá de si lo consideramos o no cabeza de serie y también de su personalidad dentro de la serie filética.

Para las figuras que nos interesan, Acosta adoptó una evolución establecida anteriormente por M. Burkitt ${ }^{22}$. A continuación la desarrolló según una lógica formal, si bien en su texto quedan expuestas sus vacilaciones $^{23}$. A nuestro entender, en los dos cuadros de sus figuras 2 y 3 hay un momento (que creemos que se sitúa entre los números 15 y 16 de la fig. 2) en que la serie se rompe para pasar directamente a las formas circulares o aproximadamente cuadradas o rectangulares. No pretendemos decir que esas abstracciones no representen figuras humanas, sino que dificilmente se puede mantener la secuencia cuando se están utilizando items de casi toda la Peninsula. Otra cosa sería si el material empleado correspondiera a una región o zona muy concreta. Así, por ejemplo, Pilar Acosta incluye en ese su primer grupo a las figuras en "phi" que para nosotros pueden emparentarse directamente con los arqueros levantinos de la fase final y que tendria su propia evolución, si bien también es posible que nuestra amiga y colega tenga razón y en su favor están las figuras de La Graja de Jimena (Jaèn) ${ }^{24}$, aunque cabría asimismo una recurrencia paralela. Podriamos también hablar del origen de la forma "golondrina", pero ello nos alejaria del tema que aquí nos interesa.

Una notable aportación de Pilar Acosta son sus mapas de distribución, que es algo que se encuentra a faltar en la gran obra del abate Breuil. Los mapas de Acosta relacionados con las figuras que estamos estudiando son los que llevan los números 2 y 3 de su libro ${ }^{25}$, en los que separa las representaciones "esquemáticas" de las de "brazos en asa" (en "phi" según el pequeño dibujo), o sea que reparte en ambos su categoria 1. . En el mapa número 2 se indican 231 puntos y en el número 3,68 puntos, por tanto casi 300 lugares sobre un total de casi 400 conocidos para todo el arte esquemático en el momento de publicar la obra (1968). A ello habría que añadir los numerosos descubrimientos posteriores y seria deseable que alguien emprendiera la tarea de poner dicho atlas al dia. La figura humana de brazos y piernas en arco es seguramente el grafema

\footnotetext{
"Henri Breull y M. C. Burkitt, Rock paintings of Southern Andalusia, a description of a Neolithic and Cooper Age Art Group, Oxford, Clarendon Press, 1929, pág. 5, fig. 1. Parece más lógica la evolución presentada en la fig. 5 de esta misma obra.

23 Acosta, La pintura rupestre esquemática..., cit., págs. 25-26.

24 BreulL, Les peintures rupestres schématiques..., cit., t. IV, págs. 5-8, láms. I-III.

Acosta, La pintura rupestre esquemática..., cit., págs. 193-197.
} 
esquemático más frecuente en territorio español. En los mapas de Pilar Acosta (que no incluyen Portugal) se observa que la mayor concentración de las mismas se da en Sierra Morena y la Andalucia oriental, incluida la zona del Estrecho.

Si se acepta que existe un «proceso de esquematización» ${ }^{26}$, que llega a sus últimas consecuencias con la abstracción, y parece que esto nadie lo pone en duda, debemos señalar nuestro desconocimiento de los mecanismos que van eliminando los detalles que permiten una aproximación al significado de las figuras. Creemos que es evidente que esto no ocurrió de lo simple a lo complejo, como queria nuestro amigo el barón Alberto Carlo Blanc en el título Dall'astrazione all'organicità, de uno de sus libros $^{27}$, sino absolutamente al contrario. Siguiendo al abate Breuil, Blanc, en dicha obra, partia de la idea de la unidad total del arte prehistórico paleolítico, postpaleolítico europeo, e incluso el exótico. Pero, en su texto - que más de treinta años después de haber sido publicado todavia merece ser leido-, no entraba en el problema de la coexistencia del gran arte naturalista y el de las abstracciones simbólicas durante el Paleolitico superior, ni se referia a los procesos varios de rápida evolución iconológica de los tiempos postpaleoliticos ${ }^{28}$.

Se ha repetido con frecuencia que de la pictografia a la escritura sólo hay un paso. Pero esta es una cuestión en la que aqui no entraremos, dejándola para otra ocasión o en otras manos. Lo que no hay que dejar de señalar es el interés que reviste el problema del por qué de los pasos sucesivos en dicho camino. Creemos personalmente que la mayoria de ellos se reflejaron en las paredes rocosas de cuevas y abrigos tras sufrir los cambios sobre otros soportes. Pensamos, por ejemplo, en que entre los materiales a los que su técnica de elaboración "obliga» a la esquematización están la cesteria y el tejido. Pero tampoco en este caso podemos extendernos, dejando para otra circunstancia la exposición detallada de esta posibilidad. Lo mismo hay que decir de los simbolismos esquemáticos, su origen y su valor, dentro de nuestro mundo contemporáneo.

26 Además de los ya citados: E. Ripol Perello, "The process of schematisation in the prehistoric Art of the Iberian Peninsula", (Peter J. Ucko, ed.). Form in indigenous Art of aboriginal Australia and prehistoric Europe, Canberra, 1977, págs. 418-428, 9 figuras.

Alberto CaRlo Blanc, Dall'astrazione all'organicità. Roma. De Luca, 1958. Dicho título invertia el de un opúsculo de Ranuccio BIANCHI BALDINELl.I. Organicità e Astrazione, Roma, Feltrinelli, 1956.

${ }^{2 B}$ Compárese, por ejemplo, el lento ritmo cronológico de la invención de lo que en el arte paleolitico se denomina "animación", con el que hay entre un estilizado arquero de la fase dinámica levantina y un stick-man del final de la facies esquemática dentro del arte postpaleolitico. 
Pero debemos volver al hilo de nuestra disgresión. En efecto, acaso pudo ocurrir que los antropomorfos esquematizados hubieran llegado con las influencias mediterráneas que dan la clave para otras representaciones esquemáticas que encontramos en la Península Ibérica. Se trata de un grafema tan simple y tan expresivo que su difusión pudo ser muy rápida. Al propio tiempo esto pudo influir en su perduración temporal y en la creación de variantes ${ }^{29}$.

La hipótesis del origen extrapeninsular no puede ser descartada, a la vista de las representaciones de este tipo o emparentadas que se encuentran en el mundo mediterráneo y alpino, pero también habrá que tener en cuenta las fechas respectivas y por tanto la posibilidad de "reflujo" desde la Peninsula Ibérica, del que ya hemos hablado en alguna otra ocasión ${ }^{30}$, o de unas evoluciones recurrentes in situ. A continuación nos referimos a este mundo externo, pero inmediato, a la Peninsula Ibérica en relación con el tipo de representación del que nos estamos ocupando. Aunque intencionadamente nos limitaremos en la búsqueda de paralelos, que podría alargarse mucho, ya hemos insinuado y a continuación haremos referencia a la amplia difusión geográfica en el Mediterráneo occidental del grafema humano de brazos y piernas en arco que es el que está representado en la Piedra Marés.

Cuevas, abrigos e hipogeos de Italia y sus islas muestran pinturas y grabados esquemáticos con una notable diversidad de estilos. Las formas humanas muy esquemáticas aparecen ya en el Neolítico. Así, por ejemplo, conocemos un típico "orante" grabado sobre hueso con una compleja decoración geométrica hallado en el Riparo Gaban, cerca de Trento, en un estrato de la cultura de los Vasos de Boca Cuadrada (Museo Tridentino di Scienze Naturali) ${ }^{31}$. A nuestro juicio podría ser un eco de las representaciones del no lejano Neolítico balcánico. Con más seguridad está relacionado con el mundo alpino de los grabados, que tuvo una larga duración.

Los grandes conjuntos de Valcamonica ${ }^{32}$ y del Monte Bego ${ }^{33}$ y otros menores de la Valtellina, Lago de Garda, Liguria y Piamonte, constituyen,

${ }^{2}$ La existencia de este tema iconográfico a escala mundial mereceria ser estudiado. Sin ninguna duda uno de los focos creadores es el Próximo Oriente, asi en el Neolitico anatólico con formas emparentadas aunque no idénticas con las de la Peninsula lbérica. James MELLAART, Çatal Hüyük, a neolithic town in Anatolia, Londres, Thames and Hudson, 1967 (trad. francesa, París, Tallandier, 1971).

${ }^{30}$ E. Ripoll Perello, "Nota acerca de las pinturas rupestres de la Grota Scritta, en Olmeta-du-Cap (Córcega)", Ampurias, XXIX, 1967, págs. 262-267, II láms.; ID., "Cuestiones en torno a la cronologia...", citado. III.

"Paolo Grazıosı, L'arte preistorica in Italia, Florencia, Sansoni, 1973, págs. 94-95, lámina

${ }^{32}$ Por ejemplo, en Foppe di Nadro y en Naquane, aunque en estos lugares las figuras 
en efecto, una importante provincia de arte rupestre que tiene sus propios mecanismos de estilización y esquematización que no creemos que tengan una inmediata relación con los propios del arte esquemático de la Península Ibérica. En cambio, sí la tienen, a nuestro parecer, otros sitios italianos: las islas de Cerdeña -y Córcega, su vecina francesa-, Sicilia y Levanzo (ésta en el archipiélago de las Egadas, al noroeste de Sicilia), y los continentales, entre los que destaca la Cueva de Porto Badisco (Otranto, Lecce), uno de los conjuntos de arte esquemático más importantes de Europa. Curiosamente, entre el gran número de figuras de esta cavidad, para la que contamos con la importante monografia que le dedicó el recordado Paolo Graziosi, hay muy pocos antropomorfos que puedan relacionarse con los de la Piedra Marés ${ }^{34}$. Aunque es mucho menor el número total de figuras (un centenar), no ocurre lo mismo con el conjunto pintado de la Grotta Genovese, en la isla de Levanzo ${ }^{35}$, cavidad en la que también existen grabados paleoliticos ${ }^{36}$. Las figuras humanas, todas en color negro, muestran diversas fases de esquematización que parece iniciarse con una variante del "hombre lagarto" y culminan en formas abstractas. Una de ellas es el llamado “idolo violón», representación de la "diosa madre» que procede de Creta, las Cicladas, Tesalia y Troya. Graziosi atribuye al conjunto una edad neo-eneolitica. Pero hay que subrayar que todas las figuras de este friso (fig. 4) son contemporáneas, o

humanas más frecuentes tienen los brazos levantados en posición de "oferente" u "orante". Emmanuel ANATI, La grande roche de Naquane, Archives IPH, mem. 31. Paris, 1960; Io., Evoluzione e stile nell'arte rupestre camuna, Capo di Ponte, CCSP, 1975; lo., Valcamonica: 10.000 anni di Storia, Capo di Ponte, CCSP, 1980.

${ }^{33}$ Trabajos recientes: Henry DE LUMLEY, et al., "La stèle gravée dite du "Chef de tribu" dans la région du Mont Bego, Vallée des Merveilles, Tende, Alpes-Maritimes", L'Anthropologie, 94, 1990, pág. 3-62, 63 figs, al que sigue otro trabajo sobre el traslado de dicha pieza. Anteriormente: la obra básica de C. BICKNELL, Guida delle incisioni rupestri preistoriche nelle Alpi Marittime italiane, Bordighera, ILSL, 1971 (trad. de la edición original inglesa de 1913); H. DE Lumley, H. Fonvielle y J. Abelanet, "Les gravures rupestres de l'Áge du Bronze dans la région du Mont-Bego (Tende, Alpes Maritimes)", IX Congrès UISPP, Nice, 1976, Colloque XXVII, Les gravures préhistoriques dans les Alpes, págs. 7-34.

${ }^{34}$ GraziosI, L'arte preistorica in Italia, cit., págs. 136-145, láms. 154-167 y XVII-XVIII; ID., Le pitture preistoriche della grotta di Porto Badisco, Florencia, Giunti Martello, 1980, 196 págs., XXV tablas, 128 láms. y 2 mapas. Las tablas I a IV muestran las diversas formas de la figura humana existentes en la cueva (72 variantes).

${ }^{35}$ Paolo Grazıosi, «Le pitture e i graffiti preistorici dell isola di Levanzo nell'arcipelago delle Egadi (Sicilia)", Rivista di Scienze Preistoriche, V, 1950, págs. 1-43; ID., Levanzo, pitture e incisioni, Florencia, Sansoni, 1962; ID., Larte preistorica in Italia, cit., págs. 134-135, fig. 4 y láms. 148-153; L. Bernabo Brea, Sicilia, Barcelona, Argos, 1962, págs. 21-24, lám. 2.

${ }^{36}$ La coexistencia de arte paleolitico y arte neo-eneolitico o de la Edad del Bronce se produce en otros lugares; por ejemplo, ampliamente, en la rondeña cueva de La Pileta. H. Breuil, H. Obermaier y W. Verner, La Pileta à Benaojan (Málaga), Mónaco, Chêne, 1915, 68 págs., 26 figs. y XXII láms., pero en elia no hay antropomorfos del tipo que nos ocupa. 


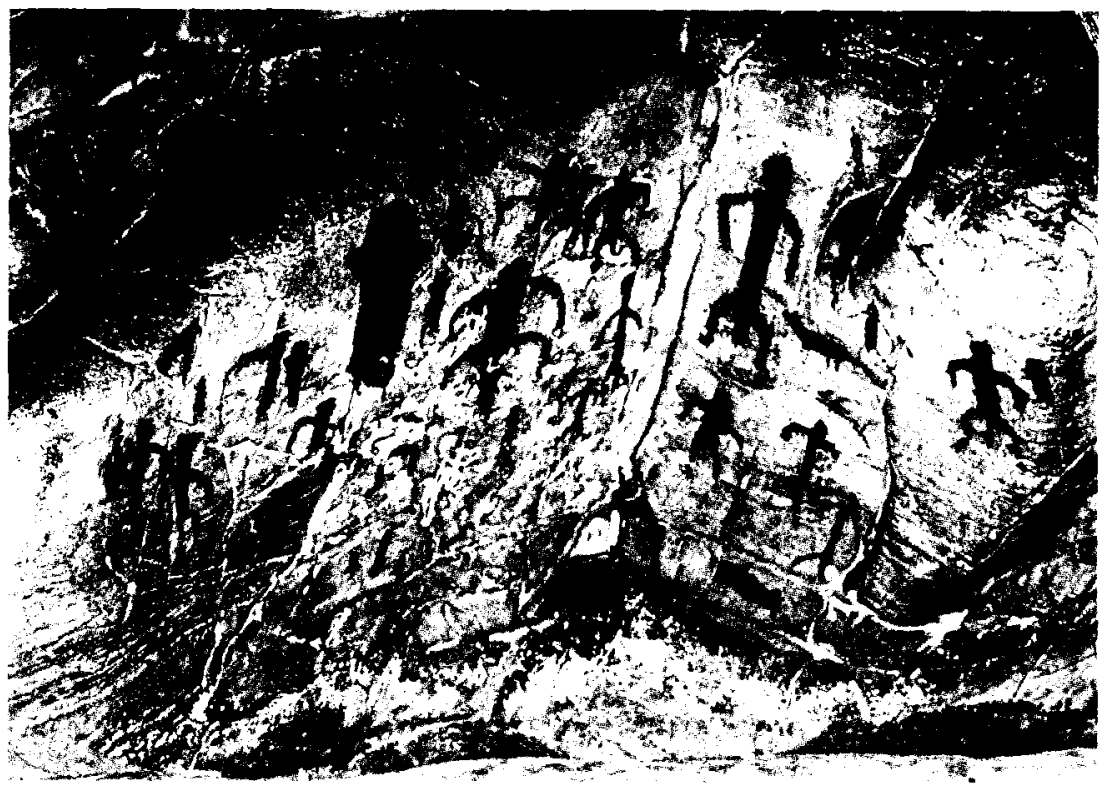

Fig. 4. Pinturas esquemáticas de la Grotta Genovese (Leranzo, Sicilia).

lo son aproximadamente. ¿Corresponde cada tipo a una diferente identificación sexual, vestimentaria o de categoría social? Por nuestra parte pensamos que estos conjuntos de la Italia meridional forman parte de la que - tomando la palabra de la lingüística- podriamos llamar koiné mediterránea que se va perfilando desde el Neolítico y la Edad del Bronce.

En cambio creemos que es un caso de "reflujo" el del pequeño friso rupestre de Olmeta-du-Cap (Capo Corso, al sur de la isla de Córcega) atribuido por todos sus estudiosos a la Edad del Bronce ${ }^{37}$. En él hay dos figuras de tipo Marés y otras emparentadas, entre ellas un gran "hombre lagarto" cornudo, situado en el centro del panel. En la vecina isla de Cerdeña hay una abundante presencia de arte esquemático, seguramente con desarrollo autóctono en su mayor parte. Como especialmente interesantes, entre las numerosas tumbas hipogeas sardas hay una treintena de domus de janas que presentan decoración grabada y restos casi desaparecidos de pinturas. Como ejemplo citaremos lo mucho recogido en

3) Roger Grosjean, La Corse avant l'histoire, París, 1966, págs. 20-21, lám. 4; Ripol. PE. RELLó, "Nota acerca de las pinturas rupestres de la Grotta Scritta..., citado; Ripoll, "Cuestiones en torno...", cit., págs. 188-189, fig. 8; Antonio Beltran, La cueva de Ussat les Eglises y tres nuevos abrigos con pinturas de la Edad del Bronce, Monografias arqueológicas, $\mathrm{V}, \mathrm{Za}$ ragoza, 1969, págs. 73-81. 
la obra de Giuseppa Tanda al ocuparse del bello conjunto de Sos Furrighesos-Anela (Sássari) ${ }^{38}$. Pero, mientras que en este lugar los ancoriformes son muy abundantes, faltan las representaciones que aqui nos interesan. Creemos que deben existir en Cerdeña y que habria que buscarlas en los muchos abrigos y cuevas que la isla presenta.

Probablemente con contactos con ese mundo del Mediterráneo central, hay que citar asimismo el arte esquemático del sur de Francia -por ejemplo, el grupo de antropomorfos de la Grotte Toulousanne (Sainte Anned'Evenos, Var) ${ }^{39}$-, si bien, para su origen, al menos parcial, personalmente nos inclinariamos a admitir una procedencia de tierras meridionales, por el valle del Segre ${ }^{40}$ o por la costa. Aunque seguiremos recordando que por tratarse de un tipo iconográfico primario, por su misma simplicidad debió circular rápidamente y adquiriendo así un carácter ubicuo.

Tampoco es mucha la precisión cronológica, al igual que es dificil la atribución cultural, de los numerosos paralelos pintados o grabados sobre roca que se hallan en territorio español. Prescindiremos de los grabados - por ejemplo, los de Piedras Huecas (Sisibaile, Jaén) publicados por Javier Fortea ${ }^{41}-y$ nos fijaremos únicamente en los que nos ofrecen los abrigos pintados. Para ello citaremos a continuación una serie de datos tomados en una rápida y somera recensión de algunas obras antiguas o recientes y sin ningún afán de exhaustividad ${ }^{42}$.

Empezaremos señalando algunos de los que recoge el abate Breuil en sus Peintures rupestres schématiques, indicando que para el sabio maestro de esta forma típica de los antropomorfos con extremidades «en áncora" se pasa a las formas "ancoriformes" y en "phi». De dicho gran corpus hemos entresacado los siguientes lugares que contienen nuestro tipo

${ }^{38}$ Giuseppa TANDA, Arte e religione della Sardegna preistorica nella necropoli de Sos Furrighesos-Anela (SS), 2 vols., Sássari, Chiarella, 1984.

${ }^{39}$ Jean AbELANET, Signes sans paroles, Paris, Hachette, 1986, pág. 159.

40 Recientemente los lugares de esta región han sido reunidos en (Josep CASTELLS i CAMP, dir.), Inventari del Patrimoni Arqueológic de Catalunya. Corpus de pintures rupestres. 1, La Conca del Segre, Barcelona, Diputació de Lleida y Direcció General del Patrimoni Cultural de la Generalitat de Catalunya, 1990. Acerca de esta obra: Eduardo RIPOLL PERELLo, "La catalogación del arte prehistórico: el "Corpus" de pinturas rupestres de Cataluña", ETF, serie I. Preh. y Arqueol., t. IV, 1991, págs. 313-323

${ }^{41}$ Javier ForTEA, "Grabados rupestres esquemáticos en la provincia de Jaén», Zephyrus, XXI-XXII, 1970-1971, págs. 139-156, 2 figs., 2 cuadros y III láminas. El antropomorfo de brazos y piernas en arco es su tipo 8a. El trabajo ofrece un agudo planteamiento acerca de la cronologia de los grabados rupestres postpaleoliticos y en especial la de los cruciformes con peana que, en tantos casos, son plenamente históricos.

${ }_{42}$ Este análisis hubièramos debido extenderlo al territorio portugués, pero es nuestro deseo no ampliar en exceso la aportación de paralelos. Como es lógico, el tipo de antropomorfos que nos ocupa también se encuentra con frecuencia en Portugal. 
de antropomorfos: Peña Tú (Llanes, Asturias), sin sexo ${ }^{43}$; Tabla del Pochico (Aldeaquemada), sin cabeza ${ }^{44}$; Covatilla del Rabanero (Sierra Madrona) ${ }^{45}$; La Batanera y Piedra Escrita de Fuencaliente (Ciudad Real), algunas con el curioso "sombrero" horizontal que también llevan las figuras humanas "en cuclillas" "46; Puerto de Vista Alegre (Sierra de Nuestra Señora del Castillo, Almadén) ${ }^{47}$; Solana de Nuestra Señora del Castillo (Almadén) ${ }^{48}$ y Las Piedras de la Cera (Lubrín, Almería), de brazos y piernas más abiertos que los de la Piedra Marés ${ }^{49}$.

Para la zona del Estrecho hemos utilizado el libro de Breuil y Burkitt. En la región gaditana las figuras de tipo Marés no son muy abundantes. En el Tajo de las figuras de la Laguna de la Janda (Benalup), contrastando con el gran número de representaciones que el lugar contiene, hallamos únicamente cinco o seis ejemplares emparentados con los nuestros, uno de ellos empuñando un arco y otro con un gran sombrero horizontal (fig. 5) ${ }^{50}$. En Palomas IV (Sierra Pedregosa) también hay cinco o seis figuras de la misma forma ${ }^{51}$. Por último, en la Cueva del Cancho (Castellar de la Frontera) hay una representación del mismo tipo, de color amarillo claro y en posición horizontal, lo que ha hecho pensar que se trata de la imagen de un difunto (además lleva un apéndice sobre su lado izquierdo que podria ser un arma) ${ }^{\text {s? }}$.

Sitos en la provincia de Córdoba podemos citar dos lugares publicados por J. Bernier y F. J. Fortea ${ }^{53}$. En la cueva de Cholones Zagrilla (Prie-

${ }^{43}$ Breuil, Les peintures rupestres schématiques..., cit., t. I, págs. 39-42, figs. 23-24. Sigue a E. Hernandez-Pacheco, J. Cabré y Conde de la Vega del Sella, las pinturas prehistóricas de Peña Tú, CIPP, núm. 2, Madrid, 1914.

${ }^{44}$ Breull, Les peintures rupestres schématiques..., cit., t. III, pág. 14, fig. 7.

45 Breull, Les peintures rupestres schématiques..., cit., t. III, págs. 64-69, figs. 32-33

46 Breull, Les peintures rupestres schématiques..., cit., t. III, págs. 81-89, figs. 39-45

A Breuil, Les peintures rupestres schématiques..., cit., t. II, págs. 14-17, fig. 15.

${ }^{48}$ BREUIL, Les peintures rupestres schématiques..., cit., t. II, págs. 17-18, lám. VI, 1.

49 Breul, Les peintures rupestres schematiques..., cit., t. IV. págs. 41-42, lám. XXXIIII.

bo Breuil y Burkit, Rock Paintings of Southern Andalusia..., cit., págs. 11-34, fıg. 34 y lámina III; Juan CABre y Eduardo HernANDEZ-PACHECo, Avance al estudio de las pinturas prehistóricas del extremo sur de España, CIPP núm. 3, Madrid, 1944. El lugar y su entorno están siendo objeto de amplio estudio por Martí MAS CORNELLÁ, “El conjunto rupestre del Tajo de las Figuras. Estado actual de las investigaciones en la Sierra Momia (Cádiz)" (E. RIPOLL Perello, ed.), Actas del Congreso Internacional "El Estrecho de Gibraltar», Ceuta, 1987, Madrid, UNED, 1988, t. I, págs. 293-303, 7 figs., entre otros trabajos.

BreuIL y BurkItT, Rock paintings of Southern Andalusia..., cit., págs. 53-55, lám. XVIII.

. Breull y Burkitt, Rock paintings of Southern Andalusia..., cit., págs. 74-75, figura 46: Acosta, La pintura rupestre esquemática..., cit., pág. 164 , fig. 55 ( $n .^{\circ} 4$ ).

$53 \mathrm{~J}$. Bernier y J. Fortea, “Nuevas pinturas rupestres esquemáticas en la provincia de Córdoba, avance de su estudio», Zephyrus, XIX-XX, 1968-1969, págs. 143-164, XII figuras. Estos autores las atribuyen al Bronce $\mid \mathrm{y}$ admiten la idea de "reflujo". 


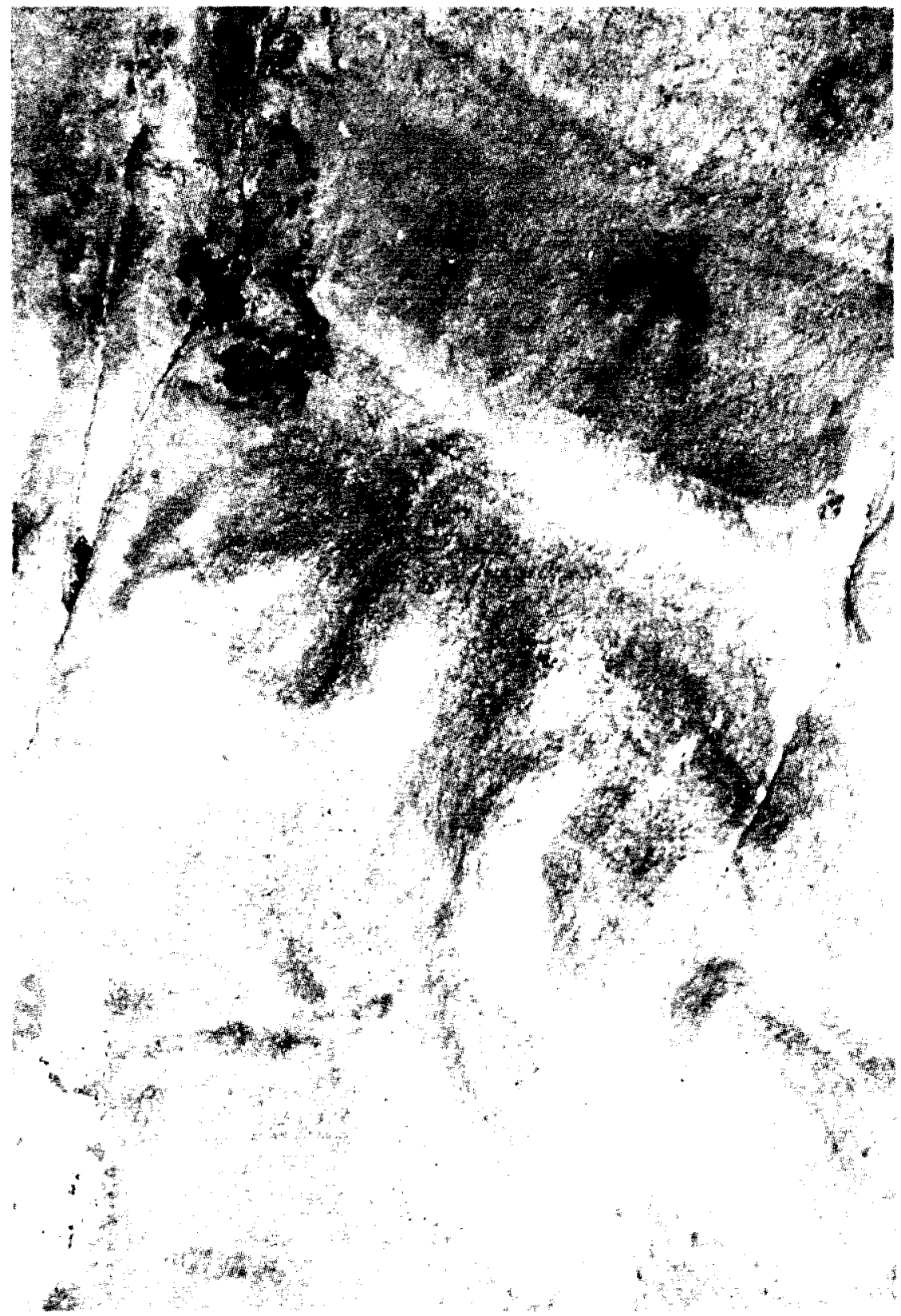

Fig. 5. Tajo de las Figuras (Laguna de la Janda, Cádiz). 
go) hay cinco figuras de color negro de tipo Marés, de forma muy alargada, para las que dichos autores plantean el problema de la perspectiva. Otras tres representaciones análogas existen en la Cueva Colorada ( $\mathrm{Ca}-$ bra), una muy estropeada, otra con exagerado sexo y otra sin él ${ }^{54}$.

M. Garcia Sánchez y M. Pellicer señalaron en la provincia de Granada diversas representaciones del tipo que nos interesa. En la comarca de Moclin se hallan la Cueva de los Limones y la Cueva del Hornillo, ambas con figuras emparentadas con las que nos están ocupando, y en Cuevas Bermejas, una figura de este tipo. En Sierra Harana, el abrigo de Julio Martínez contiene dos representaciones de la forma Marés ${ }^{55}$.

Otra obra que se ocupa del arte esquemático en la zona que como hipótesis hemos señalado como de posible origen de la Piedra Marés es la de M. G. López Payer y M. Soria Lerma ${ }^{56}$. De su amplio contenido hemos anotado los siguientes lugares (algunos ya citados por Breuil): Cueva de los Mosquitos (Aldeaquemada) ${ }^{57}$, Vacas del Retamoso (Santa Elena) ${ }^{58}$, Los Guindos (Santa Elena) ${ }^{59}$, Abrigo de Las Jaras (Santa Elena) ${ }^{60}$ y Barranco del Bu (Baños de la Encina), donde una figura lleva un doble trazo por encima de las caderas ${ }^{61}$. Las imágenes de la Piedra Marés pueden relacionarse con la mayoría de los «antropomorfos simples" de las categorias establecidas por los citados autores, en particular con las formas de «brazos en asa» - de la que los nuestros serian una

"Bernier y Fortea distinguen entre "masculino" y "femenino" en los antropomorfos según presenten falo o no. De esta Cueva Colorada, que nosotros no conocemos de visu, dicen dichos autores que presenta grandes y recientes desprendimientos (téngase en cuenta la fecha de su estudio). ¿Podria ser este el lugar de procedencia de la Piedra Marés?

${ }_{55} \mathrm{M}$. Garcia Sanchez y M. Pellicer, "Nuevas pinturas rupestres esquemáticas en la provincia de Granada", Ampurias, XXI, 1959, págs. 165-188, 11 figs. y VI láminas.

${ }^{56}$ Lopez Payer y Soria LeRma, El arte rupestre en Sierra Morena oriental, citado.

br Lopez Payer y Soria Lerma, El arte rupestre en Sierra Morena oriental, cit, pajgs. 4445, lám. 5. Se trata de seis figuras en disposición "panorámica".

${ }_{58}$ LOPEZ PAYer y Soria Lerma. El arte rupestre en Sierra Morena oriental, cit., págs. 9296, fig. 44 .

59 López Payer y Soria Lerma, El arte rupestre en Sierra Morena oriental, cit., págs. 112114, figs. 59-61.

60 López Payer y Soria Lerma, El arte rupestre en Sierra Morena oriental, cit., págs. 120122, figs. 69-70.

${ }^{61}$ Lopez Payer y Soria Lerma, El arte rupestre en Sierra Morena oriental, cit, págs. 128 131, figs. 73-77. Otros lugares citados por estos autores con figuras de las que estamos estudiando: en Aldeaquemada, el Cerro de la Caldera (págs. 38-39, lám. 3); Tabla del Pochico (págs. 51-54, lám. 11), Prado del Azogue (págs. 60-62, lám. 17) y Barranco de la Cueva (págs. 66-70, lám. 22); en Despeñaperros, el Arroyo de Santo Domingo (págs. 90-91, lám. 40) y Las Correderas (págs. 97-99, lám. 53). En el grupo de Los Guindos-El Centenillo destaca el sitio de Barranco de Doña Dama que los mismos autores publicaron en Manuel Gabriel LOPEz PAyer y Miguel Soria Lerma, "Las pinturas rupestres del "Barranco de Doña Dama" (La Carolina, Jaén)», Ars Praehistorica, III-IV, 1984-1985, págs. 271-278, 9 figuras. 
variante-, y las denominadas “tipica» y "golondrina". La calidad de su aproximación es muy notable, pues los antropomorfos en la zona por ellos estudiada son 309 (de ellos 130 en el grupo de Los Guindos-El Centenillo), que constituyen el 48,96 por 100 del total de representaciones ${ }^{62}$.

Además, tenemos otra fuente de información iconográfica en el aspecto que nos interesa, en esta ocasión para una parte de la vertiente septentrional de Sierra Morena, en la obra de A. Caballero Klink ${ }^{63}$. En ella se incluyen muchos lugares ya estudiados por Breuil -mejorando sus calcos - y aporta algunos inéditos. Se trata de un arte esquemático que, en su conjunto, nos parece más relacionado con el de Extremadura que con el de Andalucia. En Ciudad Real existen antropomorfos de brazos y piernas en arco (en su mayoría ya señalados por $\mathrm{H}$. Breuil, como hemos dicho más arriba) en el grupo de la Sierra de la Virgen del Castillo (ChiIlón): Puerto de Vistalegre, paneles 3 y 6; Roca 1 , paneles 1 y 2 , con una docena de figuras de tipo Marés; Roca 2, paneles 5 y 6 , entre otras con cuatro figuras en hilera; y Roca 3 , panel 2, con varias de la variante clargarto" "64. En el término de Fuencaliente existen en : La Batanera, sin sexo y sin cabeza; la Peña Escrita, con ocho o diez representaciones, y La Golondrina, con formas emparentadas ${ }^{65}$.

En la parte oriental de Andalucia, en la provincia de Almeria, el conjunto del Peñón de la Virgen (Gilma, Nacimiento), publicado por J. Martínez Garcia ${ }^{66}$, aporta unos notables paralelos a las figuras de la Piedra Marés. Entre muchas otras representaciones de diversas formas, el grupo más importante lo constituye la treintena de figuras del mismo tipo de las que nos vienen ocupando. De su importancia respecto al contexto habla el hecho de que constituyen un 74 por 100 del total de representaciones del conjunto.

\footnotetext{
62 Lopez Payer y Soria Lerma, El arte rupestre en Sierra Morena oriental, cit., págs. 141 y ss.. con análisis de los porcentajes en las págs. 190-196. En el núcleo de Aldeaquemada los antropomorfos son 74 (36,45 por 100 del total); en el de Despeñaperros son 81 (42,63 por 100 del total), y en Los Guindos-El Centenillo son 154 (64.70 por 100 del total).

${ }^{63}$ Alfonso CABALLERO KLINK, La pintura rupestre esquemática de la vertiente septentrional de Sierra Morena (provincia de Ciudad Real) y su contexto arqueológico, Ciudad Real, Museo, 1983 (un vol. de texto y otro de láminas)

¿ Caballero Klink, La pintura... vertiente septentrional de Sierra Morena..., cit., págs. 2338, 66-72 y 74-78, con las figuras correspondientes.

65 Caballero KLINK, La pintura... vertiente septentrional de Sierra Morena..., cit., páginas 194-200 y 221-224, con las figuras correspondientes.

tí Julián Martinez Garcia, "El Peñón de la Virgen: un conjunto de pinturas rupestres en Gilma (Nacimiento, Almeria). Asociaciones recurrentes, simbolismo y modelo de distribución», Cuadernos de Prehistoria de la Universidad de Granada, 9, 1984, págs. 39-84, 24 figs. y IV láminas.
} 
En posición geográfica marginal, o extrema, ya hemos mencionado la asturiana roca de Peña $T u ́{ }^{67}$. Le podemos añadir las dos o tres representaciones de tipo Marés que hay en el abrigo y Cueva del Ganado (Fresnedo Teverga, Asturias), publicadas por M. Mallo Viesca y M. Pérez Pérez ${ }^{68}$. $Y$ también el bello conjunto de la Cova del Demo (Boal) publicado por M. A. de Blas y E. Carrocera. En este lugar, a pesar del mal estado de conservación de las pinturas, junto con alguna emparentada, hay ocho figuras rojas del tipo que aqui nos interesa. Dichos autores llevan a cabo un sugestivo estudio de este tipo de antropomorfos que acertadamente denomina de "brazos y piernas en arco» ${ }^{68 \text { bis }}$.

En tierras más al sur, por ejemplo en el arte rupestre de las provincias de Salamanca y Zamora, este tipo de antropomorfos es menos abundante en su forma típica. Para dicho espacio geográfico contamos con la excelente obra de Ramón Grande del Brio ${ }^{69}$. Este autor menciona figuras "golondrina", "ancoriformes", o emparentadas, en los siguientes lugares: Piedras Albas (valle de Belén), Cueva del Buitre, La Tonita, Lera —en una de cuyas figuras el falo es tan exagerado que pasa a la forma "lagarto"-, Hoyita del Corcorrón y Peñas del Gato, todos ellos en la provincia de Salamanca ${ }^{70}$; y El Portillón (sierra de La Culebra), en la de Zamora, lugar en el que hay dos antropomorfos emparentados con los del tipo Marés, uno de ellos con un trazo que parece una espada y que no está descrito ${ }^{71}$. Pero no hemos sabido entender con qué criterios Grande del Brío diferencia "golondrina" de "ancoriforme». Asimismo, este autor aporta otras representaciones que pueden paralelizarse con el tipo del que nos estamos ocupando, aunque son de forma alargada y sin sexo, con diversas variantes, por ejemplo en el Risco de los Altares (valle de las

${ }^{67}$ A las referencias de Hernández-Pacheco, J. Cabré y Conde de la Vega del Sella, y a la de Breuil, hay que añadir: José Manuel Gómez Tabanera, El Peñatu de Puertas de Vidiago (Llanes, Asturias). Mito y religión de la Prehistoria astur, Pretiraje del Coloquio de Salamanca, 1982; y P. Bueno y M. Fernández-Miranda, «El Peñatu de Vidiago (Llanes, Asturias)» (M. Almagro Basch y M. Fernandez-Miranda, eds.), Altamira Symposium, Madrid, 1981, págs. 451-467, 9 láminas.

${ }^{68}$ Manuel Mallo Viesca y Manuel Pérez Pérez, "Pinturas rupestres esquemáticas en Fresnedo Teverga (Asturias)', Zephyrus, XXI-XXII, 1970-1971, págs. 105-138, 25 figs. y II láminas

68 bis Miguel A. de Blas Cortina y Elias Carrocera Fernandez, "La Cova del Demo (Boal) Una estación de arte rupestre esquemático en el occidente asturiano". Boletín del Seminario de Estudios de Arte y Arqueologia (Valladolid), LI, 1985, págs. 48-81, 19 figuras.

${ }^{69}$ Ramón Grande del Brio, La pintura rupestre esquemática en el centro-oeste de España (Salamanca y Zamora), Salamanca, 1987 (texto sobre los antropomorfos en las págs. 132133).

${ }_{70}$ Grande del Brio, La pintura... centro-oeste de España..., cit., págs. 57-59, figs. 20-21; págs. 85-87, fig. 38; págs. $87-90$, fig. 40 ; y págs. $95-97$, fig. 44 .

"Grande del Brio, La pintura... centro-oeste de España..., cit., págs. 115-117, figs. 53-54. 
Esposadas), en la Torrita 2 (en el mismo valle), la semiesquemática de la parte central del Abrigo I de Lera, o en Peñas del Gato (sierra de Zarzoso) ${ }^{72}$.

En la misma Castilla, concretamente en la altimeseta soriana, debemos señalar los estudios de J. A. Gómez Barrera que ha continuado la linea que iniciara Teógenes Ortego. Nos referimos a los datos que contiene su obra sobre las pinturas de dicha región ${ }^{73}$. En el conjunto del bello paraje del Monte Valonsadero se encuentran formas emparentadas con el tipo Marés en: Las Covatillas, Covachón del Puntal $F$ y $M$ y Peñón de la Visera ${ }^{74}$; los abrigos de Los Peñascales I, II y 111 contienen una veintena de figuras del mismo tipo o muy próximas a él ${ }^{75}$; hay que citar, asimismo, el lugar de El Pasadizo y los varios grupos de Valdecaballos, en uno de los cuales una figura de la forma que nos ocupa lleva unos grandes cuernos ${ }^{76}$. Por último, en la Cueva Grande de Oteruelos (términos de Tordasalas, Pedrajas, Villaverde y Vilviestre), en el grupo $\mathrm{H}$, hay nueve representaciones del tipo que estamos estudiando y que constituyen un probable caso de perspectiva semejante al de la Piedra Marés ${ }^{n}$.

En Extremadura se encuentra igualmente el tipo de antropomorfo con brazos y piernas en arco, aunque, con frecuencia, sin sexo y sin cabeza. En la Sierra de Arroyo de San Serván hay varios que merecen una atención especial: uno por llevar un tocado semicircular es el grafema del grupo $n .{ }^{\circ} 13$ del abrigo de Las Palomas $n .^{\circ} 2$; y también los tres que presentan unos puntos externos a la altura del pecho, del grupo n. ${ }^{\circ} 15$ del mismo lugar. Asimismo, hay ancoriformes y figuras de tipo Marés en el abrigo de Los Conejos $n .^{\circ}$. Todo ello ha sido descrito por León Gil y Garcia Verdugo ${ }^{78}$.

72 Grande del Brio, La pintura... centro-oeste de España..., cit., págs. 61-67, figs. 24-25 pág. 72 , fig. 29 ; pág. 84 , figs. 33-37; y págs. 105-112 (.$\left.^{\circ} 26\right)$.

${ }^{73}$ Juan A. GOMEZ BARRERA, La pintura rupestre esquemática en la altimeseta soriana, Soria, Ayuntamiento, 1982. Este autor tiene en prensa la obra titulada Los grabados rupestres postpaleoliticos del Alto Duero, de la que ha publicado un resumen en: Juan A. GoMEz Barrera, «Contribución al estudio de los grabados rupestres paleolíticos de la Península Ibérica: las manifestaciones del Alto Duero". ETF, serie 1, Prehistoria y Arqueologia, 4, 1991, págs. 241-268, 10 figs. (en su fig. 5 la tipología comparada de los antropomorfos pintados y grabados, en cuevas 0 al aire libre).

74 Gomez Barrera, La pintura... en la altimeseta soriana, cit., págs. 56-58, fig. 12; páginas 62-64, fig. 15; y págs. 96-99, fig. 33.

${ }^{15}$ Gomez Barrera, La pintura... en la altimeseta soriana, cit., págs. 106-114, figs. 36-39

${ }^{76}$ Gómez Barrera, La pintura... en la altimeseta soriana, cit., pág. 124, fig. 45; y páginas 126-135, figs. 47-51.

$"$ Gomez Barrera, La pintura... en la altimeseta soriana, cit., págs. 169-173, fig. 73.

${ }^{18}$ Manuel León Gil y Ramón Garcia-Verdugo Rubio, Pintura esquemática en Mérida, Sierra de Arroyo de San Serván. Badajoz, 1986, pág. 127, lám. 57; pág. 128, lám. 59; y pág. 180, lám. 95. 
También, por su localización en una zona en la que conviven la iconografia levantina y la esquemática, es muy interesante la serie de casi una treintena de antropomorfos de Hoz de Vicente (Minglanilla, Cuenca) que han estudiado M. I. Martínez Perelló y M. Díaz-Andreu ${ }^{79}$. Dentro del tipo que nos ocupa, hay en dicho lugar una gran variedad, siendo concretamente muy sugestiva una "escena" de una decena de personajes en hilera.

En la parte meridional de aquellos puntos de contacto, se hallan las localidades con pinturas rupestres de El Sabinar (Murcia). En la Cañaíca del Calar hay representaciones más o menos emparentadas con las de la Piedra Marés en los abrigos I y III. En cambio, en los abrigos de Fuente del Sabuco no hay figuras del tipo que nos interesa, pero si ufiliformes" ${ }^{80}$.

Finalmente, en este sondeo de busca de paralelos para las imágenes de la Piedra Marés, citaremos el amplio corpus del arte prehistórico alicantino de M. S. Hernández Pérez, P. Ferrer y E. Català ${ }^{81}$. En efecto, la provincia de Alicante es el núcleo en el que se encuentra el arte macroesquemático, con la presencia en su contexto de manifestaciones levantinas y esquemáticas, lo que está en la base de los muchos enigmas que aquél encierra. Señalaremos, en primer lugar, la presencia de figuras “filiformes" en el panel número 2 de La Sarga (Alcoy), que también se ven en otras cavidades de la región ${ }^{82}$. Concretamente grafemas de los que estamos siguiendo la pista se encuentra en: en el Abric VI, panel 1, de El Salt (Penáguila), con varias figuras emparentadas, dos de ellas de la forma "lagarto", una de las cuales, la más destacada, lleva dos trazos transversales sobre el pecho; la misma forma se encuentra en el Abric III, conjunto IV, del Barranc de I'Infern (La Vall de Laguart), en cuyo Abric II hay una representación típica de las que estamos estudiando ${ }^{83}$. Los citados autores realizan un detallado análisis de cada una de las fases artisticas presentes en lo que se ha convertido en una de las zonas más

Maria isabel Martinez Perello y Margarita Diaz-Andreu, «El abrigo pintado de hoz de Vicente (Minglanilla, Cuenca)", ETF, serie I, Prehistoria y Arqueologia, t. V, 1992. La "escena" en su fig. $9\left(n^{\circ} 7\right)$ e ilustraciones complementarias.

80 Antonio Beltran Martinez, Los abrigos pintados de la Cañaica del Calar y de la Fuente del Sabuco en el Sabinar (Murcia), Monografias arqueológicas, IX, Zaragoza, 1972 (su figura 94 es un cuadro de las figuras masculinas de Fuente del Sabuco).

${ }^{81}$ Mauro S. Hernandez Pérez, Pere Ferrer i Marset y Enrique Catala, arte rupestre en Alicante, Alicante, 1988. Anteriormente: M. S. Hernandez Perez y Centre d'estudis Contestans, "Consideraciones sobre un nuevo tipo de arte rupestre prehistórico", Ars Praehistorica, I. 1982, págs. 179-187, entre otras publicaciones.

82 Hernandez Pérez, Ferrer y Catala, Arte rupestre en Alicante, cit., pág. 25, fig. 5.

83 Hernandez Perrez, Ferrer y Catala, Arte rupestre en Alicante, cit., pág. 51, fig. 49; página 213. fig. 314 ; y pág. 219 , fig. 326 
densas del arte rupestre peninsular, incluido el tema de los antropomorfos esquemáticos ${ }^{84}$.

A pesar de la existencia de esa masa de documentos, y muchos otros que no hemos reseñado, tenemos que repetir que, desgraciadamente, no podemos señalar una precisa atribución cultural, y por tanto cronológica, de esa presentación iconográfica y de su contexto, Generalizando, y de conformidad con la mayoria de los autores, creemos que estas figuras pueden ser atribuidas a algún momento entre el Neolítico avanzado, el Eneolitico y la Edad del Bronce. Si para las representaciones que nos ocupan se buscan paralelos en los materiales arqueológicos, encontramos precisamente dos en yacimientos andaluces. En la Cueva del Agua de Prado Negro (Iznalloz, Granada) se hallaron dos fragmentos cerámicos con decoración de técnica impresa no cardial y con la representación de un antropomorfo simple del mismo tipo que los que estamos examinando, aunque de formas angulosas. Está realizado con una doble línea de puntillado. Al haber sido hallados los fragmentos fuera de estratigrafia, fueron atribuidos por M. S. Navarrete al Neolitico medio o final, habida cuenta de los materiales de la no lejana Cueva de La Carigüela. Otros dos fragmentos con figuras incisas - una de ellas un pequeño antropomorfofueron hallados sin contexto en la Sima LJ-11 de Salar de Loja ${ }^{85}$.

Como hemos dicho convenimos con buen número de los autores que hemos ido citando en que la facies esquemática del arte rupestre de la Península Ibérica se habria iniciado en Sudeste en el Neolitico medio o reciente a nuestro parecer - como probable evolución de las figuras levantinas «filiformes»-, propagándose con fuerza a toda Andalucia y a Sierra Morena durante el Eneolitico. Luego, durante la Edad del Bronce, se habria extendido al resto de la Peninsula, con largas perduraciones. Para este tema remitimos al cuadro - simplificador - que hemos publicado recientemente en las páginas de esta misma revista ${ }^{86}$.

${ }^{84}$ Hernandez Perez, Ferrer y Catala, Arte rupestre en Alicante, cit., pág. 287 y cuadros de las figuras 397 y 398 .

${ }_{65} \mathrm{M}$. $\mathrm{S}$. NavarRete Enciso, "Avance al estudio del material de la "Cueva del Agua" de Prado Negro (Iznalloz, Granada). Algunas cerámicas impresas" (A. BeLtrá, ed.), XIV Congreso Arqueologico Nacional, Vitoria, 1975, Zaragoza, 1977, págs. 367-376. La importancia de dicho hallazago también ha sido señalada por Javier Carrasco Rus, Ernesto Carrasco Rus, Jesús Medina Casado y Juan F. Torrecillas Gonzalez, El fenómeno rupestre esquemático en la cuenca alta del Guadalquivir. I, Las sierras subbéticas, Jaèn, 1985, págs. 144-145. figura 79 y lám. XXXVII, 4-5; y por LOPEZ PAYER y SORIA LERMA, El arte rupestre en Sierra Morena oriental, cit., pág. 432 y fig. 64 .

* Ripoll PeRello, "Acerca de algunos problemas del arte rupestre postpaleolitico en la Península Ibérica", ETF, serie I. Prehistoria y Arquelogia, 3, 1990, págs. 71-104, 13 figs. (el cuadro en la fig. 5; su antecedente - el cuadro de Wartenstein-en la fig. 3). 
En alguna ocasión hemos hablado del proceso de estilización, esquematización y abstracción en el arte prehistórico ${ }^{87}$. La Piedra Marés constituye un pequeño pero significativo documento de aquél y de su compleja problemática. La amplia difusión peninsular y extrapeninsular a la que nos hemos referido nos asegura que estamos ante un grafema de uso común en un amplísimo territorio y durante un periodo de tiempo indeterminado, pero no corto.

Más complicada, o acaso inexplicable, es la interpretación de estas figuras en relación con su complejo contexto iconográfico. En el caso de la Piedra Marés no sabemos si la "escena" está completa. De todas formas, la cohesión espacial que tienen sus figuras creemos que permite pensar en una escenificación. Por ello, como minimo y como hipótesis podriamos hablar de un grupo de figuras humanas posiblemente en actitud de danza o, acaso, de presencia ante una divinidad. Esto último seguramente sería más verosímil si los grafemas agrupados fueran del tipo "oferente" $u$ "orante". $Y$ en relación con el concepto de "grupo" o "composición» tenemos que confesar que sabemos poco. ¿Cuál era la norma -el ritmo- para las distancias entre las figuras que pueden componerlo? ¿Podemos entender, como nos parece probable, que el artista representaba de alguna forma la perspectiva o sea la situación de las representaciones entre si y en el espacio?

Al desconocimiento de estas y tantas cuestiones, sobre las que hay que seguir interrogándose, se suma, lamentablemente, la evidencia de que estos frisos han llegado hasta nosotros en muy malas condiciones de conservación y demasiadas veces mutilados. $Y$ para cerrar esta modesta contribución queremos hacer nuestras unas claras palabras de Pilar Acosta: "Lo ideal, pues, como en varias ocasiones se ha venido repitiendo, será el conocimiento de sus origenes, evolución, finales, pervivencias, significado intrínseco y función en general, todo ello dentro de unas coordenadas de tiempo y espacio, sustentadas por los contextos culturales correspondientes" ${ }^{88}$.

\footnotetext{
8i RIPOLL, "Cuestiones en torno a la cronología del arte rupestre postpaleolitico...", citado; ID., "The process of schematisation in the prehistoric Art of the Iberian Peninsula", citado; ID., "Cronologia y periodización del esquematismo prehistórico en la Península Ibérica", Zephyrus, XXVI, 1983 (F. JORDA CERDA, ed., Actas del Coloquio Internacional sobre arte esquemático de la Peninsula lbérica, Salamanca, 1982), págs. 27-35, 2 figuras.

${ }^{88}$ Pilar Acosta Martinez, "El arte rupestre esquemático ibérico: problemas de cronologia preliminares" (Javier FORTEA, ed.). Scripta Praehistorica Francisco Jordá Oblata, Salamanca. Universidad, 1984, págs. 31-61 (la cita en la pág. 32).
} 